\title{
The distribution of enteric bacteria from Australian mammals: host and geographical effects
}

\author{
David M. Gordon and Frances FitzGibbon†
}

Author for correspondence: David Gordon. Tel: +6126249 3552. Fax: +61262495573. e-mail: David.Gordon@anu.edu.au

Division of Botany \& Zoology, Australian National University, Canberra, ACT 0200, Australia

\begin{abstract}
Bacteria of the family Enterobacteriaceae were isolated from 642 mammalian hosts, representing 16 families and 79 species, collected from throughout Australia. Escherichia coli was the most common of the 24 enteric species recovered and represented almost half of the isolates. Association analysis revealed that most other species of bacteria were less likely to be recovered from hosts in which $E$. coli was present. The composition of the enteric community of a host was found to be determined by both the taxonomic family to which the host belonged and the geographical area from which the host was collected. Hosts collected from the northern areas of Queensland and the Northern Territory had more diverse enteric communities than hosts collected from New South Wales or Western Australia. Hosts of the families Petauridae and Vespertilionidae had more diverse enteric communities than did members of the Macropodidae or Phalangeridae. The probability of occurrence of Citrobacter freundii, Enterobacter cloacae, Escherichia coli, Hafnia alvei, Klebsiella oxytoca and $K$. pneumoniae in a host was found to vary with respect to host family and/or host locality. The non-random distribution of these species demonstrates the presence of extensive population structure and may suggest the existence of adaptations specific to both the primary and secondary habitats of these enteric bacteria.
\end{abstract}

Keywords: Enterobacteriaceae, mammals, distribution, host, geography

\section{INTRODUCTION}

In bacteria, genetic material is transmitted vertically as a consequence of asexual reproduction, and horizontally via the mechanisms of transduction, conjugation and transformation. The relative importance of vertical versus horizontal gene exchange will be a significant determinant of the genetic structure of bacterial populations. The method of multi-locus enzyme electrophoresis (MLEE) has provided a wealth of data concerning allele and genotype frequencies in Escherichia coli populations (Milkman, 1973; Selander \& Levin, 1980; Caugant et al., 1981, 1984; Whittam et al.,

\footnotetext{
†Present address: CSIRO Entomology, GPO Box 1700, Canberra, ACT 2601, Australia.

Abbreviations: NSW, New South Wales; NT, Northern Territory; QLD, Queensland; SA, South Australia; TAS, Tasmania; VIC, Victoria; WA, Western Australia; MLEE, multi-locus enzyme electrophoresis; PCO, principal co-ordinates analysis.
}

1983a ; Pupo \& Richardson, 1995 ; Gordon, 1997). These investigations have provided strong support for the idea that E. coli is essentially clonal (Selander et al., 1987). However, the evidence provided by the MLEE analyses is to some extent contradicted by an increasing number of nucleotide sequence studies. Many of these surveys have provided clear evidence of recombination and sometimes extensive recombination (Dykhuizen \& Green, 1986; Dubose et al., 1988; Bisercic et al., 1991; Milkman \& Bridges, 1993; Guttman \& Dykuizen, 1994; Nelson \& Selander, 1994). The apparently contradictory results of the MLEE and DNA sequence studies, clonality in the face of what appears to be 'frequent' recombination, can be reconciled if one assumes there is extensive ecological structure within the species (Maynard Smith, 1991; Cohan, 1994; Guttman, 1997). Under such a scenario, ecological structure restricts the extent of selective sweeps and the subsequent purging of genetic variation and can maintain linkage disequilibrium even in the face of high rates of recombination. 
In concert with our expanding knowledge of the forces shaping the genetic structure of E. coli populations there is growing evidence that E. coli may not serve as a paradigm for all bacterial species. Analyses of an increasing number of MLEE studies have strongly suggested that there is extensive variation among species in their genetic structure (Maynard Smith et al., 1993; Souza et al., 1993; Gordon et al., 1995; Haubold et al., 1998). For example, Salmonella enterica appears to be highly clonal whilst Neisseria gonorrhoeae does not (Maynard Smith et al., 1993).

Despite some exceptions, one of the problems that has plagued the study of bacterial population genetics has been the focus on clinical isolates from humans or domestic animals living in the developed countries of the West (Musser et al., 1985, 1986; Caugant et al., 1986; Selander et al., 1986, 1990; Whittam et al., 1993). Although the reasons for this bias are obvious, it has the consequence that much of our knowledge is based on isolates taken from a relatively homogeneous population of a single species. Indeed, the evidence suggests that there is very little geographical structure in E. coli populations from humans (Whittam et al., 1983b). Furthermore, the focus on bacteria of clinical significance has the outcome that the available data on genetic structure encompass a phylogenetically disparate group of species, with very different epidemiologies and life-history characteristics. This diversity makes it difficult to identify the factors that are contributing to the among-species variation in genetic structure.

In an attempt to address some of these problems, a survey of the enteric flora of mammals living in Australia was undertaken. The family Enterobacteriaceae is arguably the best characterized group of bacteria, thereby minimizing the problems with identification that occur with less well studied groups. Furthermore, being commensals of the gastro-intestinal tract, most species in the family have broadly similar ecologies. This paper presents the results of the survey and examines the extent to which host and geographical effects influence the structure of enteric communities as well as the distribution of individual enteric species.

\section{METHODS}

Host collection. The bacteria isolated for this study were obtained from hosts collected in an ad hoc manner from 1993 to 1997. A variety of researchers throughout Australia were asked if they would be willing to collect samples from the animals they live-trapped as part of their on-going research projects. These efforts resulted in samples being obtained from over 600 individuals representing 79 species of mammals from 16 families (Table 1). Hosts were obtained from over 75 different localities representing every state and territory (Table 1). For the purposes of this study the Australian Capital Territory was considered to be a part of New South Wales.

Faecal sample collection. Samples were collected using a sterile swab/transport tube system containing Aimes transport agar (Power \& McCuen, 1988). The samples were obtained in several ways, depending on the size and type of animal captured. For the larger species, samples were obtained by inserting the swab into the anus/cloaca of the animal. For smaller species, the swab was used to transfer fresh faecal pellets, produced while the animal was being handled, to the transport tube. Researchers collecting the samples were asked to keep the samples at $5{ }^{\circ} \mathrm{C}$, but this was not always possible under field conditions. Samples were usually shipped to the Australian National University within a week of their collection and were processed on arrival.

Isolation of bacteria. The swab was streaked over one-third of a MacConkey agar plate (Power \& McCuen, 1988) and dilution-streaked using a sterile loop over the remainder of the plate in order to produce single colonies. Following incubation, a single representative of each colony morphology present on the plate was chosen and dilution-streaked on another MacConkey agar plate and incubated. This procedure was repeated a second time. All cultures were incubated overnight at $37^{\circ} \mathrm{C}$. Subsequently, a single colony was taken from each plate and grown overnight at $37^{\circ} \mathrm{C}$ in LB broth (Power \& McCuen, 1988), after which a $1.5 \mathrm{ml}$ aliquot was transferred to a sterile storage tube containing $100 \mu \mathrm{l}$ glycerol. These cultures were stored at $-70^{\circ} \mathrm{C}$.

The aim of this study was to maximize the number of different haplotypes of each bacterial species recovered while minimizing the number of isolates requiring characterization. Previous research has demonstrated that this will be more efficiently accomplished by isolating a single clone per host and examining a large number of different individuals, rather than by taking multiple isolates from a smaller number of hosts. This outcome is a consequence of the fact that multiple isolates taken from an individual at one point in time will usually be identical (Caugant et al., 1984).

MacConkey medium is considered to be non-selective with respect to members of the Enterobacteriaceae (Ewing, 1986). Thus, the medium used should not have significantly biased the results of this study. However, the method of isolation has the consequence that usually only the most abundant species of bacteria occurring in the gut would have been recovered. It is possible that some species typically exist as minority members of the community; that is, they usually occur at a frequency of less than $10 \%$ of the total aerobic cell population. Selective plating does demonstrate that other species, such as Enterobacter cloacae, may be present in low numbers in hosts where E. coli is dominant (unpublished data). Therefore, this study is examining the distribution of those species existing as the dominant member(s) of the enteric flora of an individual host.

Identification of bacteria. All of the isolates were identified based on their biochemical profiles. At the time of isolation, any isolate with a colony morphology consistent with that of E. coli was tested for growth on minimal lactose and minimal citrate agar plates (Power \& McCuen, 1988) as well as for indole production using the BBL DMACA Indole reagent (Becton Dickinson) according to the manufacturer's protocol. The $\mathrm{Lac}^{+} \mathrm{Ind}^{+} \mathrm{Cit}^{-}$isolates were presumed to be E. coli. Subsequently, over $30 \%$ of the presumptive E. coli isolates were characterized using MLEE. In no instance did the results of the MLEE analysis suggest that any of the presumed E. coli isolates were not in fact this species (Gordon \& Lee, 1999; unpublished data).

All of the non-E. coli isolates were identified as follows. Cells from each freezer culture were dilution-streaked onto a nonselective LB agar plate. Following incubation, a single colony from each plate was dilution streaked onto a MacConkey agar plate and incubated. The biochemical profile of every isolate was determined using the BBL Crystal Enteric/Nonfermenter 
Table 1. Number of hosts and host species examined by host locality and family

\begin{tabular}{|c|c|c|c|c|c|c|c|c|c|}
\hline \multirow[t]{3}{*}{ Host family } & \multirow{3}{*}{$\begin{array}{c}\text { No. of host } \\
\text { species }\end{array}$} & \multicolumn{8}{|c|}{ No. of hosts examined } \\
\hline & & \multicolumn{7}{|c|}{ Host locality } & \multirow[b]{2}{*}{ Totals } \\
\hline & & NSW & NT & QLD & SA & TAS & VIC & WA & \\
\hline Bovidae (cattle) & 1 & 13 & & & & & & & 13 \\
\hline Burramydidae & 2 & 3 & & & 2 & & & & 5 \\
\hline Dasyuridae & 19 & 14 & 54 & & 14 & 56 & 2 & 13 & 153 \\
\hline Hominidae (human) & 1 & 3 & & & & & & 9 & 12 \\
\hline Macropodidae & 8 & 35 & 8 & & 3 & & & 27 & 73 \\
\hline Molossidae (bats) & 1 & & & & 1 & & & & 1 \\
\hline Muridae & 18 & 80 & 23 & 5 & 13 & & 19 & & 140 \\
\hline Ornithorhynchidae & 1 & & & & & 3 & & & 3 \\
\hline Peramelidae & 3 & 11 & 4 & & & 1 & & 4 & 20 \\
\hline Petauridae & 3 & 1 & & 18 & 2 & & & & 21 \\
\hline Phalangeridae & 3 & 58 & 14 & & 1 & 4 & 3 & 21 & 101 \\
\hline Phascolarctidae & 1 & & & & 1 & & & & 1 \\
\hline Potoroidae & 3 & 9 & & & 1 & & & 20 & 30 \\
\hline Tachyglossidae & 1 & & & & 8 & & & & 8 \\
\hline Vespertilionidae & 12 & 14 & 2 & & 17 & & 4 & 16 & 53 \\
\hline Vombatidae & 2 & 2 & & & 6 & & & & 8 \\
\hline Totals & 79 & 243 & 105 & 23 & 69 & 64 & 28 & 110 & 642 \\
\hline
\end{tabular}

or Rapid Stool/Enteric Identification Systems (Becton Dickinson) according to the manufacturer's protocol. In addition to each isolate's indole reaction, the oxidase reaction of every isolate was determined using the BBL Oxidase reagent according the manufacturer's protocol. These identification kits determine the reaction of the test strain to a total of 32 biochemical tests, the results are scored and the strain identified using the BBL Crystal ID System Electronic Codebook (Becton Dickinson). All isolates were tested using the Enteric/Nonfermenter test kits.

The identity of all strains determined to be Citrobacter freundii, C. amalonaticus, Hafnia alvei, Klebsiella oxytoca, $K$. pneumoniae and Serratia marcescens was supported by the results of MLEE characterization (Gordon \& Lee, 1999; unpublished data). Of the isolates not identified as the species just listed, 36\% were tested again using either the Enteric/ Nonfermenter or Rapid Stool/Enteric ID kits. In every case the original identification was confirmed.

Statistical analyses. Multiple species of bacteria were often isolated from a single host. For all possible pairwise species comparisons, contingency-table analysis was used to determine if the presence of one species influenced the likelihood that another species would be present (Ludwig \& Reynolds, 1988).

One of the questions addressed with this data set was the extent to which the flora of a host depended on its taxonomic group or the geographical locality from which the host was collected. Host group was defined as the taxonomic family to which the host species belonged. This grouping represents a compromise between maximizing resolution, while maintaining sample sizes that were sufficient for meaningful statistical analysis. For example, rodents in Australia are represented by a single family, while there are 13 families of marsupial. Hence classifying the hosts only to order level would have resulted in rodents being represented by a relatively homogeneous group of hosts, while marsupials would have been represented by a heterogeneous collection of species with very different natural histories. Classifying hosts to genus level would have reduced sample sizes to too great an extent. Geographical locality was defined as the political unit (state or territory) where the host was collected. Although this definition appears arbitrary, the majority of the samples collected came from a single region within each state. For example most WA samples were from the south-western region of the state, whilst virtually all NT samples were from Kakadu National Park in the northern part of the territory. Therefore, the majority of the localities within a state represented a single climatic region. Attempting to partition samples to represent climatic regions more precisely would have resulted in too many regions with small sample sizes.

In addressing this basic question, all 642 hosts and their associated 951 isolates were used in the analyses. One problem arising from the ad hoc manner in which the samples for this study were acquired was that it was not possible to obtain a completely balanced sampling design - that is, an equal number of hosts for each host family from every state. Although, this outcome is in part a consequence of the degree of sampling effort, achieving a completely balanced design would not be possible. No species of Australian mammal, with the exception of the echidna, is distributed throughout the country (Strahan, 1983). Furthermore, there are many genera and several families which are not represented in every region of Australia (Strahan, 1983).

There are two components to species diversity: richness (the number of species recovered) and evenness (the variability in the relative abundance of species). To determine if the number of bacterial species (species richness) recovered from a host varied among host families or geographical localities, a randomization procedure was employed (Sokal \& Rohlf, 1981). Each of the 642 hosts were assigned at random, without 
replacement, to each family or locality and the mean number of species per host for each family or locality was then calculated. This procedure was repeated 1000 times. Family and locality randomizations were calculated independently. The question being asked was - could a difference in the mean number of species per host among families or localities as large as that observed have arisen by chance? For example, hosts belonging to the family Phalangeridae had a mean of $1 \cdot 17$ species of bacteria per host, while hosts belonging to the Vespertilionidae had a mean of 1.68 species per host, a difference of 0.51 (see Table 4). In 1000 randomizations a difference as large as this was only observed $2 \cdot 0 \%$ of the time. The conclusion therefore would be that the mean number of bacterial species per host does vary significantly among host families.

The extent to which the other component of the bacterial floral diversity, evenness, varied with respect to family and locality was also examined. Evenness was assessed by calculating the probability that two hosts belonging to the same family or locality would harbour different species of bacteria. The measure used was $h_{\mathrm{g}}=1-\Sigma p_{i g}^{2}$, where $g$ denotes family or locality and $p_{i}$ the relative abundance of the $i$ th species of bacteria recovered from family or locality $g$. To assess whether the diversity of the bacterial flora varied among host families or localities, a randomization procedure similar to that described above was employed. Each host together with the species of bacteria isolated from that host were randomly assigned, without replacement, to each family or locality. The bacterial diversity for each host family or locality was then calculated. This procedure was repeated 1000 times. Again, the question posed was - could a difference in diversity among families or localities as large as that observed have arisen by chance?

Principal co-ordinates analysis (PCO) was the second approach used to investigate the extent to which the enteric community of a host was determined by its taxonomic group or geographical origin. The input for this analysis was a similarity matrix derived using the Jaccard index (JI) (Ludwig \& Reynolds, 1988): JI $=x /(x+y+z)$. Every host individual was compared with every other host individual in a pairwise fashion. $x$ is the number of bacterial species shared between hosts, $y$ is the total number of species in one host and $z$ is the total number of bacterial species in the other host.

The scores of the first PCO axis were then used as the dependent variable in a standard analysis of variance, where host family and host locality were the independent factors. Predicted values for each level within a factor (family or locality) were estimated after adjusting for the other factor.

To determine if the probability of occurrence of an individual species of bacteria differed with respect to host family or host locality, a nominal logistic regression analysis was used. The effect of each factor on the probability of occurrence was determined after adjusting for the effect of the other factor. All 642 hosts were used in these analyses, but the analyses were restricted to the most abundant species of bacteria.

A guide to Australian mammals. Many of the species discussed in this paper may be unfamiliar to many readers. A brief description of the families examined in this study and some of their relevant characteristics is therefore given here (see Strahan, 1983, for more details). The Austral-Papua region is the only area to support each of the three extant mammal radiations: Monotremata, Marsupialia and Eutheria.

Monotremata. Ornithorhynchidae: the platypus is a $1-2 \mathrm{~kg}$ solitary aquatic species which feeds predominantly on aquatic invertebrates. Tachyglossidae: the solitary terrestrial echidna weighs $2-7 \mathrm{~kg}$ and feeds exclusively on ants and termites.

Marsupialia. Dasyuridae: this is a diverse family of carnivorous species that includes the planigales, dunnarts, antechinus, quolls and Tasmanian devil. They are solitary animals that range in size from $5 \mathrm{~g}$ for the planigales to $7 \mathrm{~kg}$ for the Tasmanian devil. The small members are primarily insectivorous while the larger members eat a range of invertebrate and vertebrate prey. Peramelidae: the solitary bandicoots are terrestrial and range from 0.5 to $2 \mathrm{~kg}$ in size. They are omnivorous and their diet is dominated by invertebrates and fungi. Phascolarctidae: the koala is a solitary arboreal species which is exclusively folivorous. Vombatidae: the wombats are large $(20-40 \mathrm{~kg})$ solitary terrestrial animals that feed primarily on grasses. Petauridae: this family includes the ringtail possums and gliders. The possums are solitary, weigh from 0.5 to $2 \mathrm{~kg}$, and are arboreal. Their diet consists almost exclusively of leaves. The gliders are small (200-800 g) arboreal animals that often live in colonies. Their diet is primarily insects and plant exudates (nectar, Eucalyptus sap and Acacia gum). Phalangeridae: the solitary brushtail possums range in size from 1 to $5 \mathrm{~kg}$, are arboreal and have a very catholic diet consisting of both plants and animals. Burramydidae: the pygmy possums are small (10-20 g), mainly arboreal, solitary creatures. Some species feed primarily on pollen and nectar while others eat insects and small vertebrates. Potoroidae: the bettongs, potoroos and rat-kangaroos range in size from 0.5 to $2 \mathrm{~kg}$ and are solitary terrestrial animals with a diet that is dominated by fungi and invertebrates. Macropodidae: the wallabies and kangaroos vary greatly in size, ranging from 2 to $66 \mathrm{~kg}$. All are herbivorous, with most species feeding on grasses, but some species are browsers.

Eutheria: Chiroptera. Vespertilionidae: the bats are small (5-20 $\mathrm{g})$, insectivorous animals that often live in colonies.

Eutheria: Rodentia. Muridae: there are a variety of mice and rats endemic to Australia and they represent a diverse group of species that range in size from 10 to $1000 \mathrm{~g}$. Some species are arboreal and many are solitary, although a number of the aridzone species live in colonies. Their diets range from predominantly grasses or seeds to a mixed diet of plants, fungi and insects.

\section{RESULTS}

A total of 1038 bacteria were isolated; of these 951 $(91.6 \%)$ were members of the Enterobacteriaceae. A total of 24 species were represented (Table 2). About $9 \%$ of the isolates could not be assigned to a species despite repeated attempts to identify them. E. coli was by far the most common species and represented almost half of the isolates (Table 2). Enterobacter cloacae was the next most abundant species, occurring at a frequency of about $9 \%$. All other species occurred at frequency of less than $6 \%$.

\section{Associations among bacteria species}

A few species were found to be more likely to co-occur than would be expected by chance (contingency-table analysis, $P<0.05)$ : Citrobacter freundii/C. amalonaticus, C. freundii/Serratia marcescens, C. amalonaticus/Serratia rubidae, S. rubidae/Providencia alcalifaciens, Yersinia enterocolitica/Serratia fonticola, Y. 
Table 2. Relative abundance of the species of Enterobacteriaceae isolated during the study

\begin{tabular}{|lc|}
\hline Bacterial species & $\begin{array}{c}\text { Relative } \\
\text { abundance } \\
(\%)\end{array}$ \\
& \\
\hline Escherichia coli & $46 \cdot 0$ \\
Enterobacter cloacae & $9 \cdot 1$ \\
No identification & $8 \cdot 9$ \\
Hafnia alvei & $5 \cdot 4$ \\
Klebsiella pneumoniae & $5 \cdot 0$ \\
Klebsiella oxytoca & $4 \cdot 4$ \\
Citrobacter freundii & $2 \cdot 8$ \\
Serratia marcescens & $2 \cdot 7$ \\
Enterobacter taylorae & $2 \cdot 1$ \\
Enterobacter (Pantoea) agglomerans & $1 \cdot 9$ \\
Serratia plymuthica & $1 \cdot 8$ \\
'Salmonella enterica & $1 \cdot 5$ \\
Enterobacter aerogenes & $1 \cdot 3$ \\
Shigella dysenteriae & $1 \cdot 3$ \\
Klebsiella sp. & $0 \cdot 9$ \\
Providencia rettgeri & $0 \cdot 9$ \\
Proteus mirabilis & $0 \cdot 8$ \\
Yersinia enterocolitica group & $0 \cdot 7$ \\
Citrobacter amalonaticus & $0 \cdot 5$ \\
Morganella morganii & $0 \cdot 4$ \\
Serratia fonticola & $0 \cdot 4$ \\
Providencia alcalifaciens & $0 \cdot 3$ \\
Serratia rubidaea & $0 \cdot 3$ \\
Crovidencia sp. & $0 \cdot 2$ \\
& $0 \cdot 1$ \\
\hline
\end{tabular}

enterocolitica/Shigella dysenteriae. Enterobacter cloacae and Hafnia alvei were less likely to co-occur than would be expected by chance. By contrast, with the exceptions of Enterobacter agglomerans and Y. enterocolitica, all of the enteric species with a relative abundance of greater than $0.9 \%$ (Table 2) were significantly less likely to be isolated from hosts that harboured E. coli. All other pairwise species contrasts were not statistically significant.

\section{Bacterial species diversity}

The mean number of species recovered per host varied from 1.4 for hosts collected in NSW and WA to $2 \cdot 0$ for hosts collected from QLD (Table 3), but no significant difference in the mean number of species per host among the states could be detected (randomization test: probability of a greater difference $>0 \cdot 20$ ). The mean number of species recovered per host ranged from $2 \cdot 0$ for hosts in the family Petauridae to 1.2 for hosts in the Phalangeridae (Table 3). There were significant differences in species richness among host families (randomization test: probability of a greater difference $<0 \cdot 02$ ).

The measure of bacterial species evenness varied significantly among states, with the highest value being found
Table 3. Summary diversity statistics of the enteric communities of Australian mammals by host family and locality

\begin{tabular}{|lrcc|}
\hline & $N^{*}$ & $\begin{array}{c}\text { Species } \\
\text { richness } \dagger\end{array}$ & $\begin{array}{c}\text { Species } \\
\text { evenness } \neq\end{array}$ \\
\hline Host locality & & & \\
Queensland & 23 & $2 \cdot 0$ & $0 \cdot 90$ \\
Northern Territory & 105 & $1 \cdot 6$ & $0 \cdot 83$ \\
South Australia & 69 & $1 \cdot 5$ & $0 \cdot 83$ \\
Tasmania & 64 & $1 \cdot 5$ & $0 \cdot 64$ \\
Victoria & 28 & $1 \cdot 5$ & $0 \cdot 61$ \\
New South Wales & 243 & $1 \cdot 4$ & $0 \cdot 71$ \\
Western Australia & 110 & $1 \cdot 4$ & $0 \cdot 68$ \\
Host family & & & \\
Petauridae & 21 & $2 \cdot 0$ & $0 \cdot 91$ \\
Vespertilionidae & 53 & $1 \cdot 7$ & $0 \cdot 89$ \\
Dasyuridae & 153 & $1 \cdot 6$ & $0 \cdot 80$ \\
Potoroidae & 30 & $1 \cdot 5$ & $0 \cdot 59$ \\
Muridae & 140 & $1 \cdot 5$ & $0 \cdot 79$ \\
Macropodidae & 73 & $1 \cdot 4$ & $0 \cdot 59$ \\
Peramelidae & 20 & $1 \cdot 4$ & $0 \cdot 67$ \\
Phalangeridae & 101 & $1 \cdot 2$ & $0 \cdot 42$ \\
\hline
\end{tabular}

* Number of hosts examined.

† Mean number of bacterial species isolated per host.

$\ddagger$ Probability that two hosts from the same family or locality will harbour different species of bacteria.

in hosts collected from QLD $(0.90)$ and the lowest in hosts collected from VIC $(0 \cdot 61)$ (Table 3) (randomization test: $P<0.01$; a difference $>0 \cdot 15$ would be significant at $\alpha=0.05)$. The Petauridae had an evenness estimate of 0.91 , more than twice that of the Phalangeridae $(0.42)$ (Table 3) (randomization test: $P<0.01$; a difference $>0.24$ would be significant at $\alpha=0.05)$.

\section{Host community structure}

The first principal co-ordinates axis accounted for $30 \cdot 1 \%$ of the total variation; axes 2,3 and 4 accounted for $9 \cdot 5,7 \cdot 1$ and $5 \cdot 1 \%$ of the variation, respectively. Given that the first axis accounted for a significant amount of the total variation, subsequent analyses were restricted to the first PCO scores. The mean PCO scores varied significantly with respect to host family and host locality (analysis of variance: family $F_{(15,595)}=1 \cdot 86$, $P<0.001$; locality $F_{(6,595)}=1 \cdot 78, P<0.001$; family $/$ locality interaction $\left.F_{(25,595)}=0.34, P<0 \cdot 001\right)$. Despite there being a significant family/state interaction term, inspection of the mean square values revealed that host family or host locality individually explain more than five times the amount of variation than does the interaction term.

Although the mean PCO scores do not provide a direct description of the enteric community of a host family or geographical locality, groups with similar scores will 

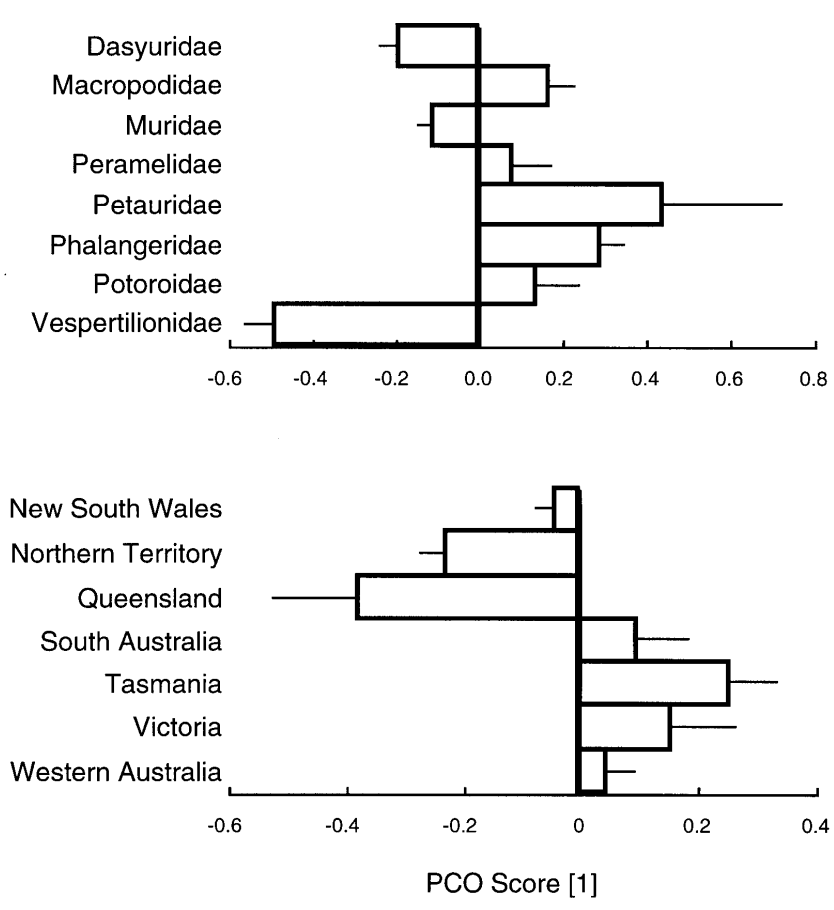

Fig. 1. Differences in the enteric community composition of Australian mammals with respect to the taxonomic family of the host and the locality where the host was collected. Bars depict the mean scores of the first PCO axis and lines the $95 \%$ confidence interval of the mean.

have enteric communities with similar species compositions (Fig. 1). Members of the Vespertilionidae have a very different enteric bacterial community compared to hosts from the other families (Fig. 1). The Dasyuridae have communities similar to those of the Muridae, and these are both different from the communities of the Macropodidae, Potoroidae, Phalangeridae and Peramelidae, which are all quite similar (Fig. 1).

The species compositions of hosts collected in NT and
QLD are similar to each other and different from the bacterial communities of hosts from other states (Fig. 1). Hosts from NSW, SA, WA and VIC have similar bacterial communities, while hosts from TAS have species compositions which differ from those of NSW, WA and SA (Fig. 1). Restricting the analysis to single families also reveals that the composition of the enteric communities differs among localities. Significant host locality effects were found for the Dasyuridae $\left(F_{(5,147)}=\right.$ $10 \cdot 23, P<0 \cdot 001)$, Muridae $\left(F_{(4.135)}=8 \cdot 47, P<0 \cdot 001\right)$ and Phalangeridae $\left(F_{(5,95)}=5 \cdot 17, P<0 \cdot 001\right)$.

\section{Occurrence of bacterial species}

The probability of occurrence for C. freundii, Ent. cloacae, E. coli, H. alvei, K. oxytoca and K. pneumoniae was found to differ significantly with respect to host family and/or host locality (Table 4; Fig. 2). The occurrence of $C$. freundii was not found to vary with respect to host family; however, this species was unlikely to be isolated from hosts living in NSW, VIC or WA. The likelihood of isolating Ent. cloacae from the families Petauridae and Phalangeridae was small, but increased in the Vespertilionidae. E. coli was the only species where the interaction between host family and locality effects was found to be significant. As a consequence, the probability of occurrence of this species in each host family was adjusted for locality effects and vice versa. $E$. coli was rare in the Vespertilionidae and relatively uncommon in the Dasyuridae. It was highly likely to be isolated from all other host families. Locality had no effect in determining whether $H$. alvei would be isolated; however it was more probable that $H$. alve $i$ would be isolated from the Dasyuridae and Muridae than any other family. A similar result was observed for $K$. oxytoca. This species was just as likely to be isolated from one locality as another, but was far more likely to be isolated from the Vespertilionidae or Petauridae. Like C. freundii, K. pneumoniae was just as common in one host family as another, but it was far more probable that this species would be discovered in a host collected in NT or QLD than most other states.

Table 4. Results of the analysis to investigate the extent to which the probability of occurrence of a bacterial species is determined by host family and locality

\begin{tabular}{|c|c|c|c|}
\hline \multirow[t]{2}{*}{ Species } & \multicolumn{3}{|c|}{ Test statistic $_{(\mathrm{df})}$ and $\boldsymbol{P}>\chi^{2}$} \\
\hline & $\begin{array}{c}\text { Family/locality } \\
\text { interaction }\end{array}$ & $\begin{array}{l}\text { Host locality } \\
\text { effect adjusted } \\
\text { for family }\end{array}$ & $\begin{array}{l}\text { Host family } \\
\text { effect adjusted } \\
\text { for locality }\end{array}$ \\
\hline C. freundii & $12 \cdot 4_{(26)} P>0 \cdot 98$ & $13 \cdot 0_{(6)} P<0.05$ & $21 \cdot 9_{(15)} P>0 \cdot 10$ \\
\hline Ent. cloacae & $31 \cdot 2_{(26)}^{(20)} P>0 \cdot 22$ & $20 \cdot 5_{(6)}^{(6)} P<0.003$ & $34 \cdot 0_{(15)}^{(10)} P<0.004$ \\
\hline E. coli & $64 \cdot 1_{(25)} P<0 \cdot 001$ & $50 \cdot 9_{(6)} P<0.001$ & $128 \cdot 2_{(15)} P<0 \cdot 001$ \\
\hline H. alvei & $15 \cdot 5_{(27)} P>0 \cdot 96$ & $12 \cdot 2_{(6)} P>0 \cdot 05$ & $43 \cdot 9_{(15)} P<0 \cdot 001$ \\
\hline K. oxytoca & $24 \cdot 8_{(26)} P>0.53$ & $8 \cdot 9_{(6)}^{(0)} P>0 \cdot 18$ & $40 \cdot 3_{(15)} P<0 \cdot 001$ \\
\hline K. pneumoniae & $25 \cdot 2_{(26)} P>0 \cdot 61$ & $45 \cdot 6_{(6)} P<0.001$ & $16 \cdot 6_{(15)} P>0 \cdot 34$ \\
\hline
\end{tabular}



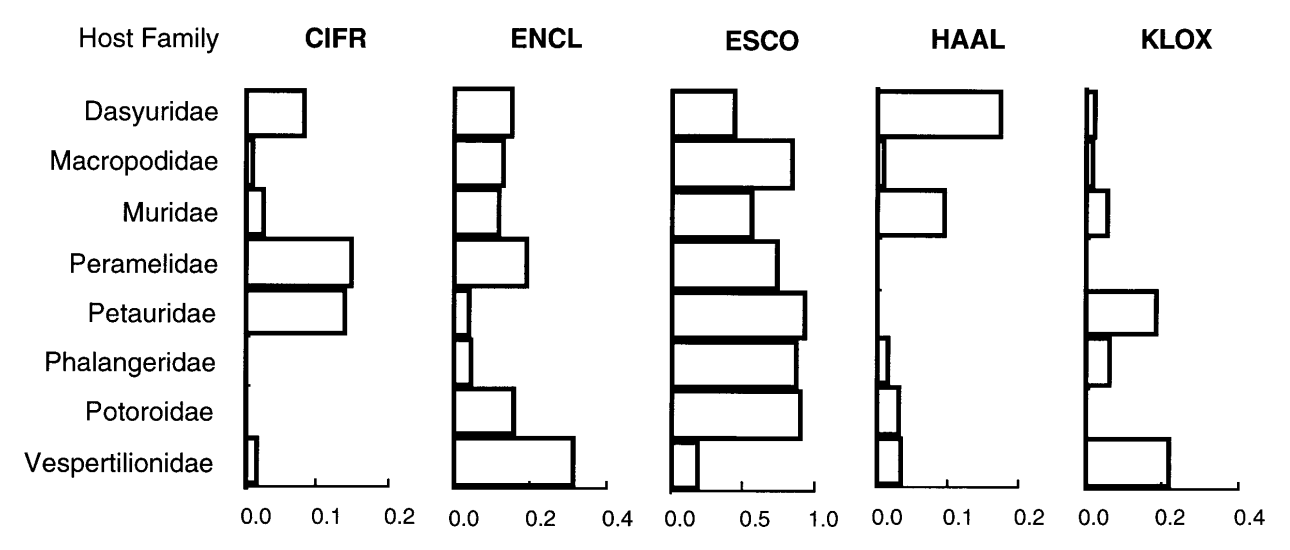

KLPN
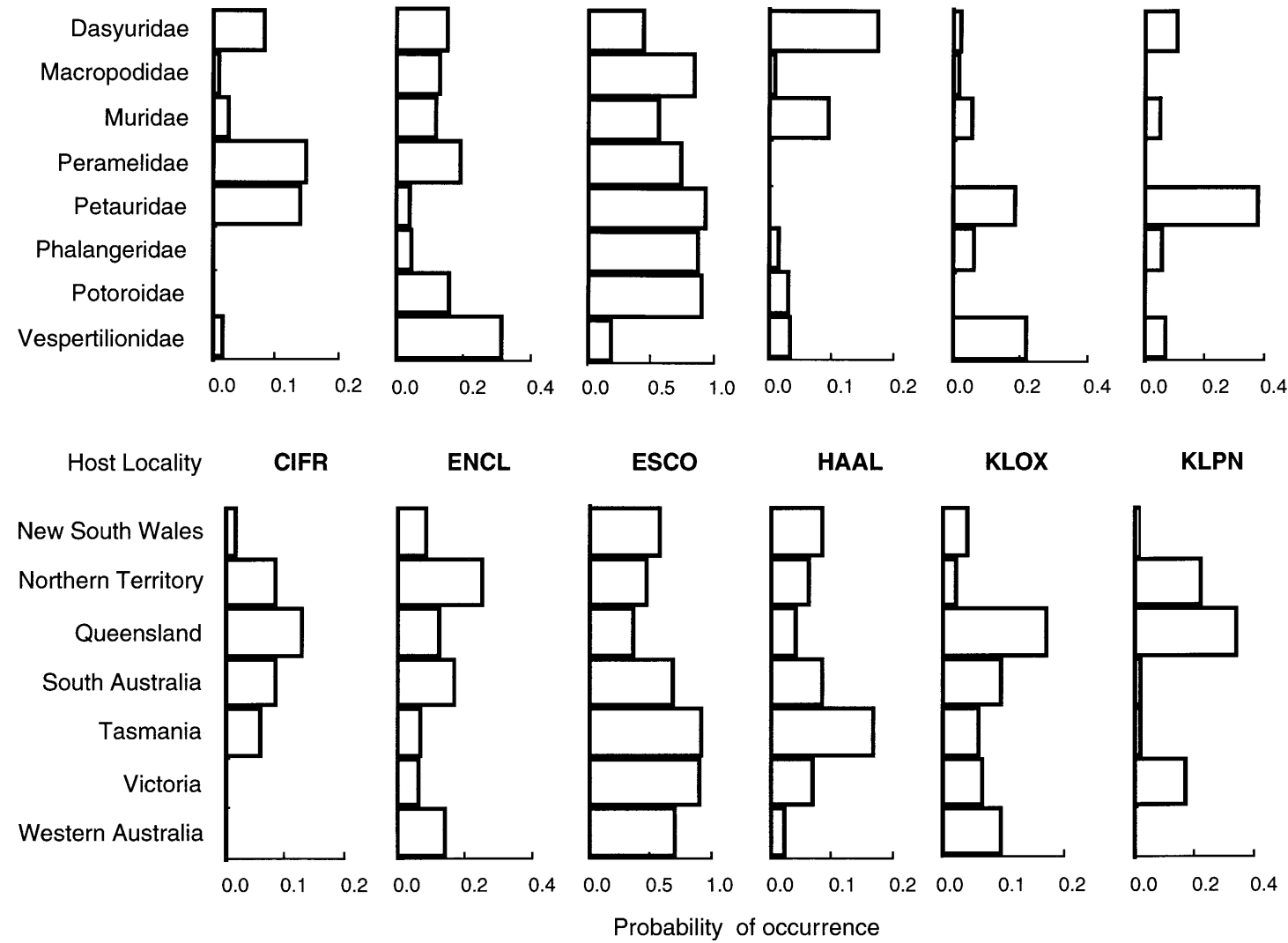

Fig. 2. Probability of occurrence of six enteric species in Australian mammalian hosts with respect to the taxonomic family of the host and the locality where the host was collected. CIFR, Citrobacter freundii; ENCL, Enterobacter cloacae; ESCO, Escherichia coli; HAAL, Hafnia alvei; KLOX, Klebsiella oxytoca; KLPN, Klebsiella pneumoniae.

\section{DISCUSSION}

The Enterobacteriaceae consists of more than 90 described species in 20 genera, although a number of these species are rarely, if ever, isolated from warm-blooded vertebrates (Ewing, 1986). Eleven genera and 24 species were identified during this study. All but $9 \%$ of the isolates collected could be assigned to a species. Typically, the identification kits used in this study successfully classify all but about $7 \%$ of Enterobacteriaceae isolated from humans (Holmes et al., 1994). Given the diversity of hosts from which the bacteria were isolated in this study, failing to name $9 \%$ of the strains is perhaps not surprising. Indeed, the probability of occurrence of the unidentified bacteria varied significantly among host families; such bacteria were more likely to have been isolated from Ornithorhynchidae, Tachyglossidae, Vespertilionidae and Vombatidae than from other host families (data not presented). Further analysis of some of the unidentified isolates using additional phenotypic criteria and the RFLP patterns of their 16S rRNA and ompA genes suggest that these strains probably represent both new species or known species which exhibit atypical biochemical profiles (unpublished data).
The enteric community composition was found to differ significantly among host families and among host localities. A large part of these differences in community composition is explained by the effect these same factors have on the distribution of the six most abundant species of bacteria. For example, hosts in the family Dasyuridae had a quite distinct enteric community compared to the other families (Fig. 1) and, in particular, showed a high species diversity (Table 3). This is reflected by the fact that five of the six abundant bacterial species were quite likely to be isolated from hosts in this family (Fig. 2). By contrast, hosts in the Macropodidae had a much different community from the Dasyuridae - one with a relatively low species diversity (Table 3). Of the six most common species, only E. coli and Ent. cloacae were likely to be isolated from these hosts (Fig. 2).

There are many factors that may be responsible for the differences in enteric communities and the distributions of particular bacterial species. The natural life cycle of the enteric bacteria is thought to consist of transitions between two distinct habitats (Savageau, 1983). The lower intestine of the animal host represents the enterics' primary habitat, whilst the environment exterior to the host (soil, sediment and water) represents their sec- 
ondary habitat. Consequently, the distribution of bacteria may be affected by two sets of environmental factors.

There are considerable differences among host families in their normal core body temperatures. These temperatures range from $30^{\circ} \mathrm{C}$ for monotremes, $35^{\circ} \mathrm{C}$ for marsupials and $38^{\circ} \mathrm{C}$ for the eutherian mammals (Schmidt-Nielsen, 1997). Gut morphology varies among families, due to both the effects of diet and phylogenic constraints. In turn, this variation will determine factors such as gut transit times (Warner, 1981; Withers, 1992). Host diet may influence bacterial community composition more directly. For example, people who consume a large amount of meat show higher numbers of Bacteroides and lower numbers of coliforms and lactic acid bacteria than do vegetarians (Madigan et al., 1997). This result is thought to be a consequence of the differences in the quantity and nature of the nutrient sources provided to the bacteria by these two diet types. Humans are thought to acquire their E. coli flora via the ingestion of contaminated food (Bettelhelm et al., 1977; Cooke et al., 1970; Caugant et al., 1981). Therefore, carnivorous hosts will likely be exposed to a wider range of bacterial species than would strict herbivores. The Dasyuridae and Vespertilionidae are all carnivorous or insectivorous and their enteric floras are some of the most diverse. By contrast, the Macropodidae are exclusively vegetarian and the Phalangeridae species examined during this study are largely vegetarian, and both these groups exhibit low levels of diversity. The distribution of K. oxytoca may also be diet-related. K. oxytoca was most likely to be observed in the Vespertilionidae and this species is commonly isolated from insects (Howard et al., 1985), which are the primary food source of this group of hosts.

There are a multitude of factors which could affect the survival of bacteria in the external environment and hence their distribution (Platz, 1980; Pedersen \& Jacobsen, 1993). The distribution of K. pneumoniae may be due to external factors. K. pneumoniae was overrepresented in the tropical regions of Australia and is the only Klebsiella species which grows at $44.5{ }^{\circ} \mathrm{C}$ but fails to grow at $4{ }^{\circ} \mathrm{C}$ (Ewing, 1986).

The distribution of enteric bacteria may be influenced by factors that extend beyond the effects of individual host species or simple locality effects. In an analysis of the distribution of 60 species of forest-inhabiting mammals in eastern Australia, Johnson (1998) demonstrated that the extent of a species' geographical distribution and its population density were positively correlated, whilst population density was positively correlated with latitude. The factors influencing mammal community structure may indirectly also affect enteric community structure.

It is well accepted (Selander et al., 1987), though perhaps not as well documented, that E. coli is the most common member of the aerobic flora of warm-blooded vertebrates. The results of this study clearly support this view. E. coli represented almost $50 \%$ of the bacteria isolated and was far more abundant than any other species. However, E. coli is not always the most common member of the aerobic flora. It was isolated from less than $50 \%$ of the hosts in the family Dasyuridae and was rare in the family Vespertilionidae. The association analyses clearly show that if $E$. coli was isolated from a particular host, then it was far less likely that another species of enteric bacteria would be isolated from that host. Why E. coli is such a dominant species is unknown.

The results of this study clearly demonstrate that species in the family Enterobacteriaceae are not distributed randomly with respect to host or geographical locality. Further work is required in order to determine the ecological characteristics of the hosts and their enteric species that are responsible for the observed distribution and community patterns. The extent to which the factors that determine the distribution of these enteric species also shape their genetic structure will be the subject of future studies.

\section{ACKNOWLEDGEMENTS}

This study could not have been undertaken without the assistance of a great many researchers throughout Australia and their help is greatly appreciated. Funding for this study was provided by the Australian Research Council.

\section{REFERENCES}

Bettelhelm, K. A., Cooke, E. M., O'Farrell, S. O. \& Shooter, R. A. (1977). The effect of diet on intestinal Escherichia coli. J Hyg 79, 43-45.

Bisercic, M., Feutrier, J. Y. \& Reeves, P. R. (1991). Nucleotide sequences of the gnd genes from nine natural isolates of Escherichia coli: evidence of intragenic recombination as a contributing factor in the evolution of the polymorphic gnd locus. J Bacteriol 173, 3894-3900.

Caugant, D. A., Levin, B. R. \& Selander, R. K. (1981). Genetic diversity and temporal variation in the E. coli populations of a human host. Genetics 98, 467-490.

Caugant, D. A., Levin, B. R. \& Selander, R. K. (1984). Distribution of multilocus genotypes of Escherichia coli within and between host families. J Hyg 92, 377-384.

Caugant, D. A., Bøvre, D., Gaustad, P., Bryn, K., Holten, E., Høiby, E. A. \& Frøholm, L. O. (1986). Multilocus genotypes determined by enzyme electrophoresis of Neisseria meningitidis isolated from patients with systemic disease and from healthy carriers. J Gen Microbiol 132, 641-652.

Cohan, F. M. (1994). Genetic exchange and evolutionary divergence in prokaryotes. Trends Ecol Evol 9, 175-180.

Cooke, E. M., Shooter, R. A., Kumar, P. J., Rousseau, S. A. \& Foulkes, A. L. (1970). Hospital food as a possible source of Escherichia coli in patients. Lancet 28, 436-437.

Dubose, R. F., Dykhuizen, D. E. \& Hartl, D. L. (1988). Genetic exchange among natural isolates of bacteria: recombination within the phoA gene of Escherichia coli. Proc Natl Acad Sci USA 85, 7036-7040.

Dykhuizen, D. E. \& Green, L. (1986). DNA sequence variation, DNA phylogeny, and recombination in E. coli. Genetics 113, S71.

Ewing, W. H. (1986). Edwards and Ewing's Identification of Enterobacteriaceae, 4th edn. New York: Elsevier. 
Gordon, D. M. (1997). The genetic structure of Escherichia coli populations in feral house mice. Microbiology 143, 2039-2046.

Gordon, D. M. \& Lee, J. (1999). The genetic structure of enteric bacteria from Australian mammals. Microbiology 145, 2673-2682.

Gordon, D. M., Wexler, M., Reardon, T. B. \& Murphy, P. J. (1995). The genetic structure of Rhizobium populations. Soil Biol Biochem 27, 491-499.

Guttman, D. S. (1997). Recombination and clonality in populations of Escherichia coli. Trends Ecol Evol 12, 16-22.

Guttman, D. S. \& Dykuizen, D. E. (1994). Clonal divergence in Escherichia coli as a result of recombination, not mutation. Science 266, 1380-1383.

Haubold, B., Travisano, M., Rainey, P. B. \& Hudson, R. R. (1998). Detecting linkage disequilibrium in bacterial populations. Genetics 150, 1341-1348.

Holmes, B., Costas, M., Thaker, T. \& Stevens, M. (1994). Evaluation of two BBL Crystal systems for identification of some clinically important gram-negative bacteria. J Clin Microbiol 32, 2221-2224.

Howard, D. J., Bush, G. L. \& Breznak, J. A. (1985). The evolutionary significance of bacteria associated with Rhagoletis. Evolution 39, 405-417.

Johnson, C. N. (1998). Rarity in the tropics: latitudinal gradients in distribution and abundance in Australian mammals. J Anim Ecol 67, 689-698.

Ludwig, J. A. \& Reynolds, J. F. (1988). Statistical Ecology. New York: Wiley.

Madigan, M. T., Martinko, J. M. \& Parker, J. (1997). Biology of Microorganisms. pp. 785-812. Upper Saddle River, NY : Prentice Hall.

Maynard Smith, J. (1991). The population genetics of bacteria. Proc R Soc Lond Ser B 245, 37-41.

Maynard Smith, J., Smith, N. H., O’Rourke, M. \& Spratt, B. G. (1993). How clonal are bacteria? Proc Natl Acad Sci USA 90, 4384-4388.

Milkman, R. (1973). Electrophoretic variation in Escherichia coli from natural sources. Science 182, 1024-1026.

Milkman, R. \& Bridges, M. M. (1993). Molecular evolution of the Escherichia coli chromosome. IV. Sequence comparisons. Genetics 133, 455-468.

Musser, J. M., Granoff, D. M., Pattison, P. E. \& Selander, R. K. (1985). A population genetic framework for the study of invasive diseases caused by serotype b strains of Haemophilus influenzae. Proc Natl Acad Sci USA 82, 5078-5082.

Musser, J. M., Hewlett, E. L., Peppler, M. S. \& Selander, R. K. (1986). Genetic diversity and relationships in populations of Bordetella spp. J Bacteriol 166, 230-237.

Nelson, K. N. \& Selander, R. K. (1994). Intergeneric transfer and recombination of the 6-phosphogluconate dehydrogenase gene (gnd) in enteric bacteria. Proc Natl Acad Sci USA 91, 10227-10231.

Pedersen, J. C. \& Jacobsen, C. S. (1993). Fate of Enterobacter cloacae JP120 and Alcaligenes eutrophus AE0106(pR0101) in soil during water stress: effects on culturability and viability. Appl Environ Microbiol 59, 1560-1564.

Platz, S. (1980). Studies on survival of Salmonella typhimurium in different types of soil under outdoor climatic conditions. Zentbl Bakteriol Mikrobiol Hyg Ser B 171, 256-268.

Power, D. A. \& McCuen, P. L. (1988). Manual of BBL Products and Laboratory Procedures, 6th edn, Cockeysville, MD: Becton Dickinson Microbial Systems.

Pupo, G. M. \& Richardson, B. J. (1995). Biochemical genetics of a natural population of Escherichia coli: seasonal changes in alleles and haplotypes. Microbiology 141, 1037-1044.

Savageau, M. A. (1983). Escherichia coli habitats, cell types, and molecular mechanisms of gene control. Am Nat 122, 732-744.

Schmidt-Nielsen, K. (1997). Animal Physiology, 5th edn. Cambridge: Cambridge University Press.

Selander, R. K. \& Levin, B. R. (1980). Genetic diversity and structure in Escherichia coli. Science 210, 545-547.

Selander, R. K., Korhonen, T. K., Vaisanen-Rhen, V., Williams, P. H., Pattison, P. E. \& Caugant, D. A. (1986). Genetic relationships and clonal structure of strains of Escherichia coli causing neonatal septicaemia and meningitis. Infect Immun 52, 213-222.

Selander R. K., Caugant, D. A. \& Whittam, T. S. (1987). Genetic structure and variation in natural populations of Escherichia coli. In Escherichia coli and Salmonella typhimurium: Cellular and Molecular Biology, pp. 1625-1648. Edited by F. C. Neidhardt and others. Washington, DC: American Society for Microbiology.

Selander, R. K., Beltran, P., Smith, N. H. \& 7 other authors (1990). Evolutionary genetic relationships of clones of Salmonella serovars that cause human typhoid and other enteric fevers. Infect Immun 58, 2262-2275.

Sokal, R. R. \& Rohlf, F. J. (1981). Biometry, 2nd edn. New York: W. H. Freeman.

Souza, V., Nguyen, T. T., Hudson, R. R., Piñero, D. \& Lenski, R. E. (1993). Hierarchical analysis of linkage disequilibrium in $\mathrm{Rhi}$ zobium populations: evidence for sex? Proc Natl Acad Sci USA 89, 8389-8393.

Strahan, R. (1983). Complete Book of Australian Mammals. Melbourne: Angus \& Roberston Publishers.

Warner, A. C. I. (1981). Rate of passage of digesta through the gut of mammals and birds. Nutr Abstr Rev 51B, 789-825.

Whittam, T. S., Ochman, H. \& Selander, R. K. (1983a). Multilocus genetic structure in natural populations of Escherichia coli. Proc Natl Acad Sci USA 80, 1751-1755.

Whittam, T. S., Ochman, H. \& Selander, R. K. (1983b). Geographic components of linkage disequilibrium in natural populations of Escherichia coli. Mol Biol Evol 1, 67-83.

Whittam, T. S., Wolfe, M. L., Wachsmuth, I. K., Ørskov, F., Ørskov, I. \& Wilson, R. A. (1993). Clonal relationships among Escherichia coli strains that cause hemorrhagic colitis and infantile diarrhoea. Infect Immun 61, 1619-1629.

Withers, P. C. (1992). Digestion. In Comparative Physiology, pp. 897-947. New York: Saunders Publishing.

Received 10 March 1999; revised 21 June 1999; accepted 1 July 1999 